\title{
Approaches to the Management of Elective Patients in General Surgery During Covid-19 Pandemic
}

ISSN: 2578-0379

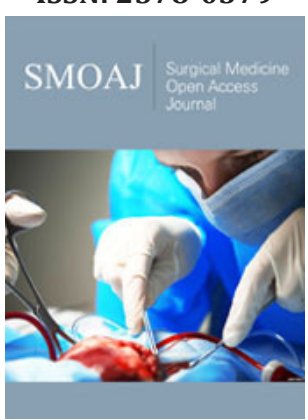

*Corresponding author: Aktokmakyan TV, Merkez mah. Bagcilar Education and Research Hospital, Bagcilar, Istanbul, Turkey, Email: talarim@gmail.com

Submission: 眥 January 22, 2021

Published: 紫February 11, 2021

Volume 4 - Issue 2

How to cite this article: Serhat $M$, Talar VA*, Merve T, Nihat B, Orxan V, et al. Approaches to the Management of Elective Patients in General Surgery During Covid-19 Pandemic. Surg Med Open Acc J. 4(2). SMOAJ.000583. 2021. DOI: 10.31031/SMOAJ.2021.04.000583

Copyright@ Talar VA, This article is distributed under the terms of the Creative Commons Attribution 4.0 International License, which permits unrestricted use and redistribution provided that the original author and source are credited.

\section{Meric S, Aktokmakyan TV*, Tokocin M, Bugdayci N, Valiyev 0, Hacim NA and Yavuz E}

Department of General Surgery, Istanbul Bagcilar Training and Research Hospital, Istanbul, Turkey

\begin{abstract}
Objective: Recently published papers have defined the clinical characteristics and overall outcomes of COVID-19 patients with the influence on the healthcare system. Especially, general surgeons are uniquely affected due to the broad range of procedures they perform, many of which are conducted routinely in the outpatient setting. This report aims to represent the clinical presentation and outcomes of elective surgical patients during the COVID-19 epidemic.
\end{abstract}

Methods: We designed a retrospective study of elective surgeries from 13 March to 13 May 2020 in Bagcilar Training and Research Hospital, a pandemic hospital in this period.

Results: 45 patients included in the study underwent different severity and morbidity operations with general anesthesia. The ratio of female to male was $23 / 22$. The mean age was 55 years. Mean Body Mass Indexes (BMI) was $28,5 \mathrm{~kg} / \mathrm{m} 2$. There were 13 co-morbid patients. The severity of the operations ranges from anal fistulectomy to abdominoperineal resection. Need for ICU developed in 9 patients (20\%). Complications developed in only one of the patients, resulting in mortality $(2,2 \%)$.

Conclusion: Surgeons as leaders need to make the best decisions for their patients while being sensitive to the broader implications. The important aim is to protect patients as well as the medical team from unnecessary infection and to keep the healthcare system study effectively. There is a need for continuous adaptation of recommendations and guidelines in order not to deprive patients of their operations, whether COVID-19 positive or not.

Keywords: COVID-19; Elective surgery; General surgery

\section{Introduction}

COVID-19, the novel coronavirus, pneumonia pandemic has affected the globe leading to many reports of incidence and mortalities. According to the World Health Organization (WHO), as of 10 AM CEST 17 May 2020, 4.529.027 people were infected while 307,565 people have died so far. Recently published papers have defined the clinical characteristics and overall outcomes of COVID-19 patients with the influence on the healthcare system [1]. To reduce disease transmission and protect personal protective equipment, and as a conclusion of widespread recommendations, surgeons have witnessed one of the most stunning changes in their practices with quickly reducing numbers of elective surgeries. Especially, general surgeons are uniquely affected due to the broad range of procedures they perform, many of which are conducted routinely in the outpatient setting. Interpreting the meaning of the word "elective" and balancing this definition with the health of the patient can be difficult even for the most experienced surgeons. Little is acknowledged regarding surgical practice in the preliminary phase of the COVID-19 pandemic. This report aims to represent the clinical presentation and outcomes of elective surgical patients during the COVID-19 epidemic.

\section{Methods}

We designed a retrospective study of elective surgeries from 13 March to 13 May 2020 in Bagcilar Training and Research Hospital, a pandemic hospital in this period, after ethical approval was taken from both local ethics committee and the Ministry of Health. Supplementary consent was obtained from patients that their operations would be performed in a pandemic hospital. 
Result

From a total of 45 initial patients, whose data is shown in Table 1 . The ratio of female to male was $23 / 22$. The mean age was 55 years (range 27-79 years). Mean Body Mass Indexes (BMI) was $28,5 \mathrm{~kg} / \mathrm{m}^{2}$ (range $\left.17,6-42,1 \mathrm{~kg} / \mathrm{m}^{2}\right)$. There were 13 comorbid patients like hypertension (HT), Diabetes Mellitus (DM), Chronic Arterial Disease (CAD), Arterial Fibrillation (AF), Chronic Kidney Disease (CKD). (Tables 1 \& 2). 45 patients included in the study underwent different severity and morbidity operations and these operations are indicated in Table 3. The severity of the operations ranges from anal fistulectomy to abdominoperineal resection. All these operations were performed under general anesthesia (Table 3). Need for ICU developed in 9 patients (20\%). Four of the patients were followed up in the intensive care unit for precautionary measures due to the morbidity of the operation and the remaining five patients due to their concomitant diseases (Table 4). 3 of 45 were clinically suspected with COVID-19. Their real-time reverse transcription-polymerase chain reaction (rtPCR) tests for severe acute respiratory syndrome coronavirus (SARS-CoV-2) was performed from a nasopharyngeal swab, were negative. However, their scannings of Computerized Tomography (CT) were suspicious with consolidation areas. Only these patients had COVID-19 pneumonia and specific medication. These three suspicious patients were those who underwent ileostomy closure, debulking, and Abdominoperineal resection operations. All three patients did not need ICU and were discharged without problems in the expected time (Table 5). While 23 of $45(51,1 \%)$ patients were operated on due to malignancy; 22 patients were operated on for benign reasons. Complications developed in only one of the patients, resulting in mortality $(2,2 \%)$. The patient with CKD as a comorbid disease previously had a kidney transplant. The patient underwent total thyroidectomy for malignant reasons, and hematoma developed after the operation, and therefore was operated on for the second time on the same day. his follow-up continued in the intensive care unit, his respiratory parameters worsened, and the patient died post-operative 6th day.

Table 1: Characteristics of included patients.

\begin{tabular}{|c|c|}
\hline Patients & $45(\mathrm{n})$ \\
\hline Female/Male & $23 / 22$ \\
\hline Mean Age & $55[27-79]$ \\
\hline Mean BMI & $28,5 \mathrm{~kg} / \mathrm{m}^{2}[17,6-42,1]$ \\
\hline Comorbid patients & $13^{*}$ \\
\hline Benign/Malign & $22 / 23$ \\
\hline ICU needed patients & 9 \\
\hline Complication & 1 \\
\hline Mortality & 1 \\
\hline
\end{tabular}

*Comorbid patients were explained in Table 2.

Table 2: Co-morbidities of included patients.

\begin{tabular}{|c|c|}
\hline \multicolumn{2}{|c|}{ Co-morbidities } \\
\hline HT & 10 \\
\hline DM & 4 \\
\hline CAD & 1 \\
\hline AF & 1 \\
\hline CKD & 1 \\
\hline
\end{tabular}

Table 3: Type of performed elective operations.

\begin{tabular}{|c|c|}
\hline \multicolumn{2}{|l|}{ Elective Operations during COVID-19 Pandemic $(n=45)$} \\
\hline Abdominoperineal resection & 1 \\
\hline Anal fistulectomy & 1 \\
\hline Anterior Resection/ Laparoscopic Anterior Resection/Low Anterior Resection & $1 / 2 / 1$ \\
\hline Debulking & 1 \\
\hline Fundoplication & 1 \\
\hline Gastrectomy Subtotal/Total & $1 / 1$ \\
\hline Gastrostomy & 1 \\
\hline Hernioraphy (Inguinal, Insicional, Umblical, Spigelian) & $3 / 3 / 1 / 1$ \\
\hline Hydatid cyst excision & 1 \\
\hline Ileostomy Closure & 2 \\
\hline Laparoscopic Cholecystectomy & 10 \\
\hline Laparoscopic Sleeve Gastrectomy & 1 \\
\hline Modified Radical Mastectomy & 4 \\
\hline Segmental Mastectomy+Centinal Lymph Node Dissection & 5 \\
\hline Total Thyroidectomy & 2 \\
\hline Rectal polyp excision & 1 \\
\hline
\end{tabular}


Table 4: List of operations applied to patients who need ICU.

\begin{tabular}{|c|c|}
\hline Operations Applied to Patients who Need ICU & (n=9) \\
\hline Laparoscopic / Convansional Anterior Resection & 2 \\
\hline Total /Subtotal Gastrectomy & 2 \\
\hline Laparoscopic Cholecystectomy & 2 \\
\hline Hydatid Cyst Excision & 1 \\
\hline Total thyroidectomy & 1 \\
\hline Laparoscopic Sleeve Gastrectomy & 1 \\
\hline
\end{tabular}

Table 5: Parameters about COVID-19 infection.

\begin{tabular}{|c|c|c|}
\hline \multirow{2}{*}{ Pymphtomatic patients } & Fever & 1 \\
\cline { 2 - 3 } & Cough & 1 \\
\cline { 2 - 3 } & Dispnea & 0 \\
\hline Positive COVID-19 Test & & 0 \\
\hline Positive BT findings & & 3 \\
\hline
\end{tabular}

\section{Discussion}

Covid-19 emerged in Wuhan in December 2019; SARS-CoV-2 has infected more than $4,000,000$ people with a large number of deaths worldwide. SARS-CoV-2 is highly infectious and is susceptible to all populations not only comorbid patients. Although the rate of comorbid patients is $28.8 \%$ in our study, it is quite clear that all patients, except one, were discharged without any problem. Covid-19 is mainly manifested as fever, accompanied by cough, fatigue, muscular soreness, chest depression, shortness of breath, diarrhea, and other symptoms. Postoperative patients may also have fever, cough, and chest condition, which should be differentiated from Covid-19 [2]. Covid-19 can be infected without any of the symptoms mentioned and the person can continue to be infectious [3]. Pre-symptomatic transmission can occur in $6.4 \%$ of all patients, it has been reported to occur at a rate of $12.6 \%$. Therefore, asymptomatic patients should be concerned, and routine blood tests, chest CT and SARS-CoV-2 nucleic acid examination should be performed before surgery [4].

Many studies suggested that surgery may accelerate and exacerbate CoVid-19 progression. There is a need for continuous adaptation of recommendations and guidelines in order not to deprive patients of their operations, whether COVID-19 positive or not [5]. Although our hospital is a pandemic hospital since March 13, in terms of general surgery elective procedures, urgent procedures and emergency procedures have been performed. As stated in our study, only one patient that we performed while in a pandemic hospital was ex. The operation of this patient was carried out on March 14 (the day after the date of the pandemic hospital) and it was suspected whether the added lung problem was due to COVID. Apart from this patient, no complications and morbidity were experienced in elective cases during this period and even the number of surgeries with high morbidity is high in number. This preliminary observational study has major limitations. First, the small number of patients included. Moreover, the period of inclusion and observation is short. On the other hand, we think that the results are enlightening in terms of the covid pandemic that is tried to be solved. Given the rapid extended of the pandemics, high mortality, and resulting disruption of social functionality, we believe the recommended measures have an appropriate benefit/ risk ratio and should be considered in a scientifically controlled setting [6].

\section{Conclusion}

Surgeons as leaders need to make the best decisions for their patients while being sensitive to the broader implications. To challenge the COVID-19, significant changes in the substructure of outpatient units, inpatient units, and operating rooms are needed. Besides, the demands regarding personal protective equipment have increased significantly. The important aim is to protect patients as well as the medical team from unnecessary infection and to keep the healthcare system study effectively. So, every effort should be taken to make the essential requirements.

\section{References}

1. (2020)" Coronavirus disease 2019 (COVID-19) Situation report World Health Organization, 118.

2. Diagnosis and treatment guideline of Covid-19.

3. Li Y, Peng S, Li L, Wang Q Ping W, et al. (2020) Clinical and transmission characteristics of Covid-19-A retrospective study of 25 cases from a single thoracic surgery department. Current Medical Science 40(2): 1-6.

4. Kimball A, Hatfield KM, Arons M, James A, Taylor J, et al. (2020) Asymptomatic and presymptomatic SARSCoV-2 infections in residents of a long-term care skilled nursing facility-King County, Washington, March 2020. MMWR Morb Mortal Wkly Rep 69(13): 377-381.

5. Lei S, Jiang F, Su W, Chen C, Chen J, et al. (2020) Clinical characteristics and outcomes of patients undergoing surgeries during the incubation period of COVID-19 infection. The Lancet 21: 100331.

6. Hlavaty T, Krajcovicova A (2020) Novel unorthodox strategies to reduce the case fatality rate of covid-19 in high-risk groups. Bratisl Lek Listy 121(7): 462-465. 